\title{
Comparison of ultrasound-guided core biopsy versus fine-needle aspiration biopsy in the evaluation of salivary gland lesions
}

\author{
Nicholas J. Douville, MSE, ${ }^{1,2}$ Carol R. Bradford, MD* \\ ${ }^{1}$ Department of Biomedical Engineering, University of Michigan, Ann Arbor, Michigan, ${ }^{2}$ Medical Scientist Training Program, University of Michigan, \\ Ann Arbor, Michigan, ${ }^{3}$ Department of Otolaryngology-Head and Neck Surgery, University of Michigan, Ann Arbor, Michigan.
}

ABSTRACT: Ultrasound-guided core biopsy provides many benefits compared with fine-needle aspiration cytology and has begun to emerge as part of the diagnostic work-up for a salivary gland lesion. Although the increased potential for tumor-seeding and capsule rupture has been extensively discussed, the safety of this procedure is widely accepted based on infrequent reports of tumor-seeding. In fact, a review of the literature shows only 2 cases of salivary tumor seeding following biopsy with larger-gauge needle characteristics, with 2 reported cases of salivary tumor seeding following fine-needle aspiration cytology. However, the follow-up interval of such studies ( $<7$ years) is substantially less than the 20-year follow-up typically necessary to detect remote recurrence. Studies on tumor recurrence of pleomorphic adenoma, the most common salivary gland lesion, suggest that as many as $16 \%$ of tumor recurrences occur at least 10 years following initial surgery, with average time to recurrence ranging anywhere from 6.1 to
11.8 years postoperatively. Despite the benefits of ultrasound-guided core biopsy over fine-needle aspiration biopsy, which include both improved consistency and diagnostic accuracy, current studies lack adequate patient numbers and follow-up duration to confirm comparable safety profile to currently accepted fine-needle aspiration cytology. In this report we: (1) compare the relative benefits of each procedure, (2) review evidence regarding tumor seeding in each procedure, (3) discuss time course and patient numbers necessary to detect tumor recurrence, and (4) describe how these uncertainties should be factored into clinical considerations. (C) 2012 Wiley Periodicals, Inc. Head Neck 35: 1657-1661, 2013

KEY WORDS: ultrasound-guided core biopsy, fine needle aspiration, tumor tract seeding, salivary gland lesions, pleomorphic adenoma

\section{INTRODUCTION}

Ultrasound-guided core biopsy offers quantifiable benefits in the assessment of salivary gland tumors compared with the long-accepted standard, fine-needle aspiration cytology, specifically the following: improved sensitivity and specificity, decreased inadequacy rate, and increased consistency. ${ }^{5,6}$ These benefits must be weighed against the potential for increased complication risks including: (1) hemorrhage, (2) facial nerve injury, and (3) tumor-seeding. Although such risks intuitively increase with the more invasive, larger-diameter ultrasound-guided core biopsy procedure, quantifying relatively infrequent complications through formal analysis has proven difficult, in part, because of the large population numbers and long follow-up duration necessary. In fact, initial studies have reported a relatively similar clinical safety profile between these 2 techniques. Based on initial studies, which reported no cases of tumor seeding following corebiopsy of 438 lesions followed for 7 years, ${ }^{1}$ and limited

*Corresponding author: C. R. Bradford, Department of Otolaryngology/Head and Neck Surgery, University of Michigan Medical Center, Ann Arbor, MI. E-mail: cbradfor@umich.edu

This work was supported by The University of Michigan Medical Scientist Training Program Grant NIGMS T32 GM07863. case reports of tumor-seeding, ${ }^{7,8}$ the safety of ultrasoundguided core biopsy has become widely accepted. ${ }^{9}$ This widespread adoption of ultrasound-guided core biopsy remains concerning because published reports lack the statistical power and follow-up necessary to detect tumorseeding. We review the advantages of each technique, highlight existing clinical and basic science evidence regarding the potential risk for recurrence with each technique, detail the expected time course for recurrence of salivary gland tumors, and discuss how this should focus future scientific inquiry and clinical decision making.

\section{Background}

Biopsy informs clinical decision making regarding management of parotid-gland lesions. After initial imaging (usually via ultrasound or MRI), a biopsy can distinguish between neoplastic lesions (which are usually managed surgically) and non-neoplastic lesions (which are usually managed conservatively). Furthermore, biopsy can potentially distinguish between benign and malignant neoplasms, which guides the extent of the surgical dissection. Open, cervical node biopsy prior to definitive treatment was shown to increase rates of local cervical recurrence and distant metastasis, as well as decrease survival rate ${ }^{10}$ compared with patients who had no biopsy or biopsy only at the time of definitive treatment. These findings ended the routine use of open biopsy for salivary gland tumors 
and focused on preoperative diagnostic techniques, which also minimized the potential for tumor-seeding and capsule rupture.

Whereas preoperative diagnostics are not essential to the management of all salivary gland lesions, because resection with intraoperative frozen sections remains a reasonable alternative, diagnostic procedures such as fineneedle aspiration cytology and ultrasound-guided core biopsy allow improved counseling and operative planning in the setting of malignant tumors. Fine-needle aspiration cytology emerged as the initial diagnostic procedure of choice. Although the potential for tumor seeding has been shown to vary greatly based on the type of tumor and anatomic site, analysis of 11,700 abdominal biopsies performed with fine needles (defined as 20-, 21-, 22-, and 23-gauge) demonstrated sufficiently low rates of tumor seeding $(0.017 \%)$ to justify preoperative utility. ${ }^{11}$ A study limited to biopsies of salivary gland adenomas found the presence of tumor cells along the needle track immediately following aspiration with a 22-gauge needle, but were not able to demonstrate increased tumor recurrence at 5-year follow-up, ${ }^{12}$ further supporting the safety and promoting the widespread adoption of fine-needle aspiration in the evaluation and management of salivary lesions. Ultrasound-guided core biopsy has more recently emerged as an alternative to fine-needle aspiration cytology. ${ }^{13,14}$ Whether improved diagnostic accuracy and decreased rates of sample insufficiency compared with fine-needle aspiration justify the increasingly invasive procedure and potentially higher rate of complications (including facial nerve damage, hemorrhage, tumor track seeding, or capsule rupture) remains unanswered. ${ }^{15}$

\section{Advantages of ultrasound-guided core biopsy compared with fine-needle aspiration cytology}

Ultrasound-guided core biopsy obtains a larger sample size for analysis than fine-needle aspiration cytology, which lowers the rate of sample inadequacy (estimated at $1.2 \%$ in ultrasound-guided core biopsy compared with $8.1 \%$ in fine-needle aspiration cytology). This is especially important at smaller medical centers where a cytopathologist cannot be on hand for immediate specimen assessment. ${ }^{16}$ Additionally, ultrasound-guided core biopsy preserves the histologic architecture of specimens, improving the accuracy of the diagnosis, and allowing additional diagnoses (eg, capsular invasion) not possible from fine-needle aspiration biopsy. Furthermore, a wider array of immunohistochemical techniques can be conducted from ultrasound-guided core biopsy samples than from fine-needle aspiration biopsy samples. These factors have led to substantial differences in reported diagnostic accuracy between the 2 techniques. Recently published meta-analyses have found that ultrasound-guided core biopsy has an overall sensitivity of 0.92 (95\% confidence interval [CI], 0.77-0.98) and overall specificity 1.00 (95\% CI, 0.76-1.00). This is compared with fine-needle aspiration cytology, which has been found to have a sensitivity of 0.96 (95\% CI, 0.83-0.99) and specificity of 0.98 (95\% CI, 0.67-1.00) for distinguishing neoplastic from non-neoplastic lesions. These numbers fall substantially, however, to sensitivity of 0.80 (95\% CI, 0.76-0.83) and specificity of 0.97 (95\% CI, 0.96-0.98), when distinguishing if such neoplastic lesions are benign or malignant. ${ }^{5,6}$

Another potential problem with fine-needle aspiration is the variability ( $\mathrm{SD}$ of sensitivity estimated at 18\%) and heterogeneity between different facilities, studies, and countries. This variability was evident in recent studies estimating the sensitivity when distinguishing benign from malignant disease as low as 0.38 (95\% CI, $0.13-0.63)^{17}$ and $58 \%{ }^{18}$ This stands in contrast to other published sensitivity values of $73 \%{ }^{19}$ and $87.8 \% .^{20}$ The wide range of sensitivity values complicates standardization of uniform recommendations regarding the utility of fine-needle aspiration biopsy compared with ultrasoundguided core biopsy and suggests that a positive diagnosis by fine-needle aspiration cytology may be reliable, although the high potential false-negative rate may require confirmation of negative diagnosis via ultrasoundguided core biopsy. 5,6

Ultrasound-guided core biopsy has also improved diagnostic accuracy in specific cytological diagnoses including pleomorphic adenoma, ${ }^{21}$ Warthin's tumor, ${ }^{22}$ and lymphoma, ${ }^{23}$ which have traditionally been difficult to diagnose via fine-needle aspiration biopsy alone. Furthermore, ultrasound-guided core biopsy may have increased diagnostic utility over fine-needle aspiration biopsy when diagnosing systemic disease such as sarcoidosis and Sjögren's syndrome.

\section{Advantages of fine-needle aspiration cytology compared with ultrasound-guided core biopsy}

The most obvious and immediately evident advantages to fine-needle aspiration cytology are that it is less painful and less frightening to the patient than ultrasoundguided core biopsy. Additionally, ultrasound-guided core biopsy requires local anesthesia and has been found to have greater morbidity (with an overall rate of hematoma estimated at $1.7 \%$, although none required treatment). The more concerning, latent, disadvantage to ultrasoundguided core biopsy is the increased potential for seeding malignant cells along the needle tract. Although cases of tumor seeding have been reported for needles as small as 23 French gauge, ${ }^{24}$ anecdotal evidence and mechanism of action suggest tumor seeding to be more common with larger needles, ${ }^{25,26}$ meaning that ultrasound-guided core biopsy (which uses a 16- to 18-gauge needle) may have increased potential for tumor seeding and capsule rupture compared with fine-needle aspiration cytology (which uses a 20-gauge or smaller). At the current time, no studies have formally evaluated the relationship between needle diameter and tumor seeding in salivary gland lesions or other, more general neoplasms. ${ }^{27}$ Furthermore, fineneedle aspiration has a theoretical lower risk for facial nerve injury, although proper identification of intraparotid vessels on ultrasound minimize risk of facial nerve damage during biopsy. ${ }^{9}$ A series of 53 patients undergoing ultrasound-guided core biopsy showed no episodes of facial nerve palsy and no recurrence due to seeding of cancer at the needle tract during follow-up of 12.2 to 77.5 months (mean follow-up is 33.6 months). ${ }^{28}$ Other studies advocating the safety and reliability of ultrasound-guided 
core biopsy were limited by a relatively brief follow-up in which there was no tumor recurrence and only small patient populations..$^{9,13,29-34}$ Novoa and colleagues ${ }^{1}$ examined the issue of tumor seeding from ultrasound-guided core biopsy in their review, finding no evidence based on 7 years of clinical follow-up in 438 lesions. Furthermore, only 2 studies characterized tumor cell displacement following core biopsy, the first using scanning electron microscopy $^{35}$ and the second with histologic examination of excised needle tracts. ${ }^{36}$ These studies reported evidence of tumor cell displacement following biopsy in 1 case of a total of 145 lesions $(0.2 \%)$, following biopsy of a malignant melanoma. 1,36

\section{Seeding of malignant cells in needle track: clinical evidence}

The risk of tumor-tract seeding varies dramatically as a function of both tumor type and anatomic site. Although needle-tract recurrences occur most commonly with pancreatic cancer, hepatocellular carcinoma, prostate cancer, and mesothelioma, reports have identified cases for nearly every tumor type including: (1) retinoblastoma, ${ }^{37}$ (2) liposarcoma, $^{24}$ (3) thymoma, ${ }^{38}$ (4) breast cancer, ${ }^{39}$ (5) thyroid cancer, ${ }^{40,41}$ and (6) CNS tumors. ${ }^{42}$ Because of this risk and the assumed relationship between needle diameter and seeding potential, certain biopsy techniques, including: (1) use of a fine, noncutting needle, (2) sample under suction, and (3) minimizing the number of passes that should be maintained to minimize the potential risk for tumor seeding. ${ }^{26}$

Initial studies on the safety of fine-needle aspiration for biopsy of salivary gland adenomas identified the presence of tumor cells along the needle-track immediately following fine-needle aspiration (22-gauge needle), but did not find an increased number of recurrences during the 5-year follow-up. ${ }^{12}$ The presence of cells in the immediate interval following biopsy highlights the risk for tumor seeding of the needle track, although the lack of recurrence suggests that salivary neoplasms (due to a combination of number of cells dislodged, adhesiveness, presence of stroma, and immunologic characteristics) are relatively resistant to tumor seeding. ${ }^{43}$ Analysis of 11 patients who had pleomorphic adenoma surgically excised following ultrasound-guided core biopsy showed no cases of tumor recurrence during the follow-up period, which ranged from 28.9 to 76.5 months (mean, 48.6 months). ${ }^{28}$ Although tumor seeding for salivary gland lesions occurs infrequently in both ultrasound-guided core biopsy and fine-needle aspiration biopsy, there have been reported cases of tumor seeding for both techniques.

The 2 earliest case reports of tumor seeding from salivary biopsy both involved needles of similar diameter to those typically used in ultrasound-guided core biopsy. ${ }^{7,8}$ Yamaguchi and colleagues ${ }^{7}$ reported of seeding a parotid carcinoma along a Vim-Silverman needle (14- to 16gauge) tract, and advised excision of the biopsy site at definitive surgery, whereas hypothesizing that biopsy with a fine needle to be less likely to promote tumor seeding. Two, more recent, cases (adenoid cystic carcinoma of the submandibular gland and pleomorphic adenoma of the parotid gland) have reported tumor seeding following fine-needle aspiration cytology. ${ }^{44,45}$

Novoa and colleagues ${ }^{1}$ recently reviewed the clinical efficacy and safety of ultrasound-guided core biopsy in the work-up of head and neck lesions. Their meta-analysis found a relatively small number of publications, which were limited by: (1) a small number of patients, (2) a short follow-up, and (3) a retrospective study design. Review of 438 lesions with 7 years of clinical follow-up found no evidence of tumor-cell seeding.

\section{Evidence for seeding along the needle tract: animal models}

Despite infrequent recurrence of salivary tumors along the needle tract in a clinical setting, animal models of salivary (as well as other types of tumors) highlight a mechanism where, at least the potential, for tumor tract seeding still strongly exists. ${ }^{46}$ Animal studies have quantified a high percentage of malignant cells following biopsy $(83 \%$ and $89 \%) .{ }^{12,47}$ Another study, in which biopsy needles (23-gauge) were passed "through" the leg muscle of a healthy mouse into a tumor-implanted mouse, demonstrated that tumor seeding occurred between $65 \%$ and $83 \%$ of the healthy animals with a seeding quantity ranging anywhere from $10^{2}$ to $10^{4}$ tumor cells per instance. These animal models demonstrate that despite technical protocol and precautions, the biopsy procedure commonly spills tumor cells into the tissue surrounding the needle tract. Clinical episodes of needle tract seeding remain relatively infrequent (the largest study following fine-needle abdominal biopsies in 11,700 patients estimated rate of tumor seeding at $0.017 \%) .{ }^{11}$ Although the mechanism behind tumor recurrence remains an area of active research, the number of seeded cells and amount of stroma seeded dictate the incidence of implantation and growth. ${ }^{48}$ Because larger-bore needles, such as those used in ultrasound-guided core biopsy, aspirate a greater number of neoplastic and stromal cells, needle diameter should be minimized while maintaining diagnostic accuracy.

\section{Recurrence of pleomorphic adenoma: frequency and time course}

Pleomorphic adenoma is the most common salivary gland neoplasm, accounting for between $50 \%$ and $70 \%$ of all salivary gland tumors. Recurrence of pleomorphic adenoma following superficial parotidectomy is estimated between $1 \%$ and $3 \% .^{51,52}$ Whereas the majority of initial recurrences occur within the first 5 to 10 years, ${ }^{53-56}$ recurrences have been reported up to 20 years following resection. ${ }^{57}$ The average duration of recurrence varies greatly in published reports, with Natvig and Soberg, ${ }^{4}$ who followed patients for an average of 18 years postoperatively, reporting a mean recurrence interval of 11.8 years postoperative, substantially longer than the 6.1 years reported by Niparko and colleagues, ${ }^{3}$ who followed their patients for an average of 16.5 years postoperatively. Furthermore, Fee and colleagues ${ }^{2}$ found that $16 \%$ of tumor recurrences took place at least 10 years following initial surgery. Another study by Stevens and Hobsley ${ }^{52}$ with a median of 4 years, showed no recurrences in 72 
patients following primary parotidectomy for pleomorphic adenoma. Such apparent differences as a function of study follow-up duration, highlights the necessity in study design for adequate length of observation to detect remote recurrence. Multiple authors recommend 20-year follow-up in this patient group. ${ }^{4,53,58}$

A review of 17 pleomorphic adenoma resections with either tumor spill or inadequate tumor resection, showed a $24 \%$ recurrence, ${ }^{59}$ although there was no recurrence in the subset of 6 patients receiving postoperative radiation. When considering only parotidectomies (excluding the 3 enucleation procedures, all of which resulted in tumor recurrence) the recurrence rate was found to be between $7 \%$ for the entire group and $13 \%$ for the cohort receiving surgery with no postoperative radiation. This number, in a population with known tumor spillage or inadequate resection, compares with an overall recurrence rate of $<2 \%$ in all parotidectomies. ${ }^{51,52,58}$ Although microscopically positive margins following resection were linked to increased tumor recurrence, tumor spill was not independently shown to be associated with an increased rate. ${ }^{59}$

\section{Role of capsule rupture on tumor seeding}

Another potential risk with the use of larger-diameter needles in ultrasound-guided core biopsy is the breach of the tumor capsule. Initial research suggested that risk of recurrence of benign salivary gland pleomorphic adenomas did not depend on capsule rupture, but on the presence of microscopic pseudopodia extending outside the pseudocapsule. ${ }^{60}$ This contrasts with a more recent study, which shows that tumor puncture and spillage are the only variables to have an independent effect on the recurrence of pleomorphic adenomas. Natvig and Soberg ${ }^{4}$ found tumor recurrence of $8 \%$ following capsule rupture compared with a baseline recurrence rate of $2.5 \%$.

\section{DISCUSSION}

The potential for tumor spillage, capsule rupture, and tumor recurrence is intuitively escalated as a function of needle diameter and sample volume. Ultrasound-guided core biopsy, therefore, potentially has an increased risk profile compared with that of the accepted fine-needle aspiration cytology technique. Despite this potential risk, studies investigating rates of tumor recurrence as a function of needle diameter (and biopsy technique) are lacking, not only for salivary gland lesions, but for all tumor types. Although animal study models suggest that tumor cells are spilled in the overwhelming majority of biopsy procedures (estimated between 65\% and 85\%), these spilled cells rarely lead to tumor recurrence, and is a function of host immunity, number of cells, and the characteristics of the tumor cell and local tissue ("seed and soil" hypothesis). Despite lower inherent tumorigenic potential of salivary gland tumors (compared with pancreatic cancer, hepatocellular carcinoma, prostate cancer, and mesothelioma), the amount of tumor cells spilled should always be minimized. Roussel and Novet ${ }^{26}$ recommend biopsy techniques, such as (1) use of a fine, noncutting needle, (2) sample under suction, and (3) minimize the number of passes.
An alternative option in the work-up of salivary gland tumors is to simply undergo parotidectomy with intraoperative frozen section (and no preoperative diagnostic maneuvers). Although certainly a reasonable alternative with the advantage of eliminating potential for preoperative tumor-tract seeding or capsule rupture, preoperative diagnosis allows for better counseling and planning for additional procedures (such as neck dissection, possible nerve sacrifice) in the setting of malignant tumors. It can also be helpful to know if a particular tumor is metastatic to the salivary gland (such as skin cancers, squamous cell carcinoma, and melanoma) rather than a primary tumor.

The short time course of postoperative histologic confirmation compared with the long time course of tumor recurrence, ensures that the benefits (increased diagnostic accuracy and consistency, decreased rates of insufficiency) are readily apparent, whereas the potential drawbacks (tumor seeding, tumor recurrence) are more latent. Since widespread adoption of ultrasound-guided core biopsy has emerged only within the last decade, and tumor recurrence occurs in such small percentages of patients (estimated between 1\% and 3\% following superficial parotidectomy) and over such a long clinical window (reports as long as 20 years postoperatively), we contend that current studies lack appropriate statistical power and follow-up necessary to confirm the safety of ultrasound-guided core biopsy. Further basic science research into the mechanisms behind seeding and correlation between needle diameter/biopsy technique and cell spillage needed. Further clinical investigation of tumor recurrence following both fine-needle aspiration cytology and ultrasound-guided core biopsy are needed in largescale patient populations over a time course as long as 20 years before the safety of ultrasound-guided core biopsy can be verified and widely accepted. Physicians should weigh the relative advantages of each technique against the supporting safety profile when determining optimal work-up of salivary gland lesions.

\section{REFERENCES}

1. Novoa E, Gurtler N, Arnoux A, Kraft M. Role of ultrasound-guided coreneedle biopsy in the assessment of head and neck lesions: a meta-analysis and systematic review of the literature. Head Neck 2012;34:1497-1503.

2. Fee WE, Goffinet DR, Calcaterra TC. Recurrent mixed tumors of the parotid gland: results of surgical therapy. Laryngoscope 1978;88:265-273.

3. Niparko JK, Beauchamp ML, Krause CJ, Baker SR, Work WP. Surgical treatment of recurrent pleomorphic adenoma of the parotid gland. Arch Otolaryngol Head Neck Surg 1986;112:1180-1184.

4. Natvig K, Soberg R. Relationship of intraoperative rupture of pleomorphic adenomas to recurrence: an 11-25 year follow-up study. Head Neck 1994; 16:213-217.

5. Schmidt RL, Hall BJ, Wilson AR, Layfield LJ. A systematic review and meta-analysis of the diagnostic accuracy of fine-needle aspiration cytology for parotid gland lesions. Am J Clin Pathol 2011;136:45-59.

6. Schmidt RL, Hall BJ, Layfield LJ. A systematic review and meta-analysis of the diagnostic accuracy of ultrasound-guided core needle biopsy for salivary gland lesions. Am J Clin Pathol 2011;136:516-526.

7. Yamaguchi KT, Strong MS, Shapshay SM, Soto E. Seeding of parotid carcinoma along Vim-Silverman needle tract. J Otolaryngol 1979;8:49-52.

8. Peacock EE Jr, Byars LT. Management of tumors of the parotid salivary gland. N C Med J 1958;19:1-9.

9. Howlett DC, Menezes LJ, Lewis K, Moody AB, Violaris N, Williams MD. Sonographically guided core biopsy of a parotid mass. Am J Roentgenol 2007;188:223-227.

10. McGuirt WF, McCabe BF. Significance of node biopsy before definitive treatment of cervical metastatic carcinoma. Laryngoscope 1978;88: 594-597.

11. Livraghi T, Damascelli B, Lombardi C, Spagnoli I. Risk in fine-needle abdominal biopsy. J Clin Ultrasound 1983;11:77-81. 
12. Engzell U, Jakobsson PA, Sigurdson A, Zajicek J. Aspiration biopsy of metastatic carcinoma in lymph nodes of the neck. Acta Otolaryngol 1971; 72:138-147.

13. Buckland JR, Manjaly G, Violaris N, Howlett DC. Ultrasound-guided cutting-needle biopsy of the parotid gland. J Laryngol Otol 1999;113: 988-992.

14. Bearcroft PWP, Berman LH, Grant J. The use of ultrasound-guided cutting-needle biopsy in the neck. Clin Radiol 1995;50:690-695.

15. Taki A, Yamamoto T, Kawai A, Terahata S, Kinuya K, Tonami H. Sonographically guided core biopsy of the salivary gland masses safety and efficacy. J Clin Imaging Sci 2005;29:189-194.

16. Eisele DW, Sherman ME, Koch WM, Richtsmeier WJ, Wu AY, Erozan YS. Utility of immediate on-site cytopathological and evaluation in fine needle aspiration biopsy of head and neck masses. Laryngoscope 1992; 102:1328-1330.

17. Balakrishnan K, Castling B, McMahon J, et al. Fine needle aspiration cytology in the management of a parotid mass: a two centre retrospective study. Surg J R Coll Surg E 2005;3:67-72.

18. Pitts DB, Hilsinger RL Jr, Karandy E, Ross JC, Caro JE. Fine-needle aspiration in the diagnosis of salivary gland disorders in the community hospital setting. Arch Otolaryngol Head Neck Surg 1992;118:479-482.

19. O'Dwyer P, Farrar WB, James AG, Finkelmeier W, McCabe DP. Needle aspiration biopsy of major salivary gland tumors. Cancer 1986;57: 554-557.

20. Jayaram B, Verma AK, Sood N, Khurana N. Fine needle aspiration cytology of salivary gland lesions. J Oral Pathol Med 1994;23:256-261.

21. Brachtel EF, Pilch BZ, Khettry U, Zembowicz A, Faquin WC. Fine-needle aspiration biopsy of a cystic pleomorphic adenoma with extensive adnexalike differentiation: differential diagnostic pitfall with mucoepidermoid carcinoma. Diagn Cytopathol 2003;28:100-103.

22. Parwarni AV, Ali-Sayed Z. Diagnostic accuracy and pitfalls in the fineneedle aspiration interpretation of Warthin's tumour. Cancer 2003;99: $166-171$

23. Loggins JP, Urquhart A. Pre-operative distinction of parotid lymphomas. J Am Coll Surg 2004;199:58-61.

24. Hidai H, Sakuramoto T, Miura T, Nakahashi M, Kikyo S. Needle tract seeding following puncture of retroperitoneal liposarcoma. Eur Urol 1983; 9:368-369.

25. Roussel F, Dalion J, Benozio M. The risk of tumoral seeding in needle biopsies. Acta Cytol 1989;33:936-939.

26. Roussel F, Nouvet G. Evaluation of large-needle biopsy for the diagnosis of cancer. Acta Cytol 1995;39:449-452.

27. Smith OD, Ellis PD, Bearcroft PW, Berman LH, Grant JW, Jani P. Management of neck lumps: a triage model. Ann R Coll Surg Engl 2000;82: 223-226.

28. Wan YL, Chan SC, Chen YL, et al. Ultrasonography-guided core-needle biopsy of parotid gland masses. Am J Neuroradiol 2004;25:1608-1612.

29. Pratap R, Qayyum A, Ahmad N, Jani P, Berman LH. Ultrasound-guided core needle biopsy of parotid gland swellings. J Laryngol Otol 2009;123: 449-454.

30. Bain B, Bearcroft PWP, Berman LH, Grantz JW. Technical note. The use of ultrasound-guided cutting-needle biopsy in paediatric neck masses. Eur Radiol 2000;10:512-515.

31. Cheung YC, Wang YL, Lui KW, Lee KF. Sonographically guided coreneedle biopsy in the diagnosis of superficial lymphadenopathy. $J$ Clin Ultrasound 2000;28:283-289.

32. Kesse KW, Manjaly G, Violaris N, Howlett DC. Ultrasound-guided biopsy in the evaluation of focal lesions and diffuse swelling of the parotid gland. Br J Oral Max Surg 2002;40:384-388.

33. Nyquist GG, Tom WD, Mui S. Automatic core needle biopsy: a diagnostic option for head and neck masses. Arch Otolaryngol Head Neck Surg 2008; 134:184-189.

34. Screaton NJ, Berman LH, Grant JW. US-guided core-needle biopsy of the thyroid gland. Radiology 2003;226:827-832.

35. Grundmann T, Hohenberg H, Herbst H. Tissue sampling in the deep headneck area with a new ultrasound-controlled, semi-automatic micro-punch biopsy device. HNO 2000;48:583-588.
36. Kraft M, Laeng H, Schmuziger N, Arnoux A, Gurtler N. Comparison of ultrasound-guided core-needle biopsy and fine-needle aspiration in the assessment of head and neck lesions. Head Neck 2008;30:1457-1463.

37. Karcioglu ZA, Gordon RA, Karcioglu GL. Tumor seeding in ocular fine needle aspiration biopsy. Ophthalmology 1985;92:1763-1777.

38. Nagasaka T, Nakashima N, Nunome H. Needle tract implantation of thy moma after transthoracic needle biopsy. J Clin Pathol 1993;46:278-279.

39. Thurfjell MG, Jansson T, Nordgren H, Bergh J, Lindgren A, Thurfjell E. Local breast cancer recurrence caused by mammographically guided punctures. Acta Radiol 2000;41:435-440.

40. Panunzi C, Paliotta DC, Papini E, Petrucci L, Rinaldi R, Nardi F. Cutaneous seeding of a follicular thyroid cancer after fine-needle aspiration biopsy? Diagn Cytopathol 1994;10:156-158.

41. Karwowski JK, Nowels KW, McDougall IR, Weigel RJ. Needle track seeding of papillary thyroid carcinoma from fine needle aspiration biopsy. Acta Cytol 2002;46:591-595.

42. Roa WH, Kim D, Halls SB, Murray B. Implantation metastasis of primary central nervous system lymphoma complicating radiotherapy outcome. Am J Clin Oncol 1999;22:29-31.

43. Smith EH. Complication of percutaneous abdominal fine-needle biopsy. Radiology 1991;178:253-258.

44. Shinohara S, Yamamoto E, Tanabe M, Maetani T, Kim T. Implantation metastasis of head and neck cancer after fine needle aspiration biopsy. Auris Nasus Larynx 2001;28:377-380.

45. Supriya M, Denholm S, Palmer T. Seeding of tumor cells after fine needle aspiration cytology in benign parotid tumor: a case report and literature review. Laryngoscope 2008;118:263-265.

46. Smith EH. The hazards of fine-needle aspiration biopsy. Ultrasound Med Biol 1984;10:629-634.

47. Struve-Christensen E. Iatrogenic dissemination of tumour cells: dissemination of tumor cells along the needle track after pecutaneous, transthoracic lung biopsy. Dan Med Bull 1978;25:82-87.

48. Hadad FS, Somsin AA. Seeding and perineal implantation of prostatic cancer in the track of the biopsy needle: three case reports and a review of the literature. J Surg Oncol 1987;35:184-191.

49. Speight PM, Barrett AW. Salivary gland tumours. Oral Dis 2002;8: 229-240.

50. Eveson JW, Cawson RA. Salivary gland tumours: A review of 2410 cases with particular reference to histological types, site, age, and sex distribution. J Pathol 1985;146:51-58.

51. Gleave EN, Whittaker JS, Nicholson A. Salivary tumors: experience over thirty years. Clin Otolaryngol 1979;4:247-257.

52. Stevens KL, Hobsley M. The treatment of pleomorphic adenomas by formal parotidectomy. Br J Surg 1982;69:1-3.

53. Krolls SO, Trodahl JN, Boyers RC. Salivary gland lesions in children: a survey of 430 cases. Cancer 1972;30:276-281.

54. Dawson AK, Orr JA. Long term results of local excision and radiotherapy in pleomorphic adenoma of the parotid. Int J Radiat Oncol Biol Phys 1985;11:451-455.

55. Smiddy FG. Treatment of mixed parotid tumours. $\mathrm{Br}$ Med $J$ 1956;1: 322-325.

56. Touqet R, Mackenzie IJ, Carruth JAS. Management of parotid pleomorphic adenoma; the problem of exposing tumour tissue at operation. The logical pursuit of treatment policies. Br J Oral Maxillofac 1990;28: 404-408.

57. Samson MJ, Metson R, Wang CC, Montgomery WW. Preservation of the facial nerve in the management of recurrent pleomorphic adeonoma. $L a-$ ryngoscope 1991;101:1060-1062.

58. Maynard JD. Management of pleomorphic adenoma of the parotid. $\mathrm{Br} J$ Surg 1988;75:305-308.

59. Buchman C, Stringer SP, Mendenhall WM, Parsons JT, Jordan JR, Cassisi NJ. Pleomorphic adenoma: effects of tumor spill and adequate resection on tumor recurrence. Laryngoscope 1994;104:1231-1234.

60. Henriksson G, Wetrin KM, Carlsoo B, Silfversward C. Recurrent primary pleomorphic adenomas of salivary gland origin. Cancer 1998;82:617-620. 